\title{
Financial Risk Assessment and Response in Practice: A Case Study of the Listed Company Shenhuo Group
}

\author{
Ran Liu \\ College of Economic Management, Dalian University, Dalian 116622, China \\ liuran@dlu.edu.cn
}

Keywords: Shenhuo group, Financing risk, Investment risk, Risk assessment.

\begin{abstract}
Financial risk is an inevitable problem in the operation of enterprises with the continuous development of market economy. In the present paper, based on the data collection of literature and financial statements of Shenhuo group, the current situation of financial risk management from four aspects: financing risk, investment risk, capital recovery risk and income distribution risk are analyzed to reduce the financial risk of enterprises. By comparing the index data of the company with the industry average, it is found that the company is in financial risk management, and the corresponding financial risk responses are put forward to enable enterprises to operate effectively in a good environment, improve management level and ability prevents risk, prompt the company's management from extensive to elaborate. At the same time, it is helpful for the listed company to prevent and avoid financial risk decision-making.
\end{abstract}

\section{Introduction}

The analysis and response of listed companies' financial risks is the focus of the economic field. Every year some large enterprises globally encounters economic difficulty and eventually go bankrupt due to out of control of financial risks ${ }^{[1,2]}$. This is a heavy blow to the normal operation of the enterprise, its industry and the entire economy and society. Listed companies may often face financial risks ${ }^{[3-5]}$. Currently free economy is increasingly complex. In the business activities associated with enterprises, the expected income is different from the real income. The expected expenditures are also different from the world's expenditures. The development of free market economy in China is booming. There are many business opportunities in the global economic market. These companies face numerous challenges and fierce competition. In the market competition, if a company wants to be invincible in multi-party competition, it must strengthen enterprise risk management and improve management quality. For one thing, we must strengthen the control of daily production and management, for another thing, we should pay more attention to the control of risks, raise awareness of risk management, adsorb the experience of others' failures, improve own defects, prevent losses in time, and eliminate the fortunes ${ }^{[1,6]}$.

In the present paper, based on the theory of financial risk, we analyze the operation of Shenhuo group in recent years from four aspects: financing, investment, capital operation and income distribution, and identify the existing and potential risks in the production and operation process to support the analysis of the existing problems and propose targeted countermeasures, avoid the losses caused by the company, increase the company's revenue, enhance the core competitiveness of the enterprise, and also finance the other enterprises and industries.

\section{Debt paying capacity analysis}

The risk of capital operation is referred as the risk caused by the variability of the time and amount of funds during the conversion process. If the funds are not recycled in time, the funds will be directly occupied by others, and the available funds will be reduced, which will affect the normal operation of the daily business activities ${ }^{[7]}$. In addition, good investment opportunities could be missed in the absence of available funds and affect long-term development of companies in a highly competitive market. For Shenhuo group, the proportion of funds occupied by inventory is very large due to the 
particularity of the industry, and the resulting risk of capital recovery is not easy to be quickly released in a short period of time.

Table 1 Inventory turnover rate of Shenhuo group in 2013-2017

\begin{tabular}{lllllll}
\hline \multirow{2}{*}{ Year } & \multirow{2}{*}{ Shenhuo } & Average & \multicolumn{3}{c}{ Corporate performance evaluation standard value } \\
& & & Excellent & Good & Normal & Bad \\
\hline 2013 & 7.63 & 5.76 & & & & \\
2014 & 5.05 & 5.48 & & & & \\
2015 & 4.11 & 2.18 & 25.7 & & & \\
2016 & 2.97 & 1.98 & & & & \\
2017 & 2.72 & 1.64 & & & & \\
\hline
\end{tabular}

The inventory turnover rate is a financial indicator of effectively assessing the inventory turnover rate over a certain period of time, and this rate is inversely related to the risk of capital recovery. According to Table 1, the inventory turnover rate of Shenhuo group has been higher than the industry average in the past five years. The inventory turnover rate is relatively leading in the industry, but it has not reached a good value, and even lower than the industry value in 2015-2017. It reveals that the inventory turnover rate of Shenhuo group has not yet reached the ideal value, and still faces certain risks in the process of capital recovery.

Table 2 Current assets, total assets, accounts receivable turnover rate statistics of Shenhuo group

\begin{tabular}{lllllll}
\hline \multirow{2}{*}{ Year } & \multicolumn{2}{l}{ Current assets rate } & \multicolumn{2}{l}{ Total assets rate } & \multicolumn{2}{l}{ Accounts receivable turnover } \\
& Shenhuo & Average & Shenhuo & Average & Shenhuo & Average \\
\hline 2013 & 2.34 & 0.77 & 0.61 & 0.57 & 71.10 & 5.83 \\
2014 & 1.75 & 0.75 & 0.50 & 0.53 & 44.66 & 5.89 \\
2015 & 1.27 & 0.68 & 0.38 & 0.49 & 39.60 & 4.66 \\
2016 & 1.10 & 0.59 & 0.33 & 0.41 & 48.03 & 4.57 \\
2017 & 1.10 & 0.81 & 0.36 & 0.39 & 82.00 & 4.85 \\
\hline
\end{tabular}
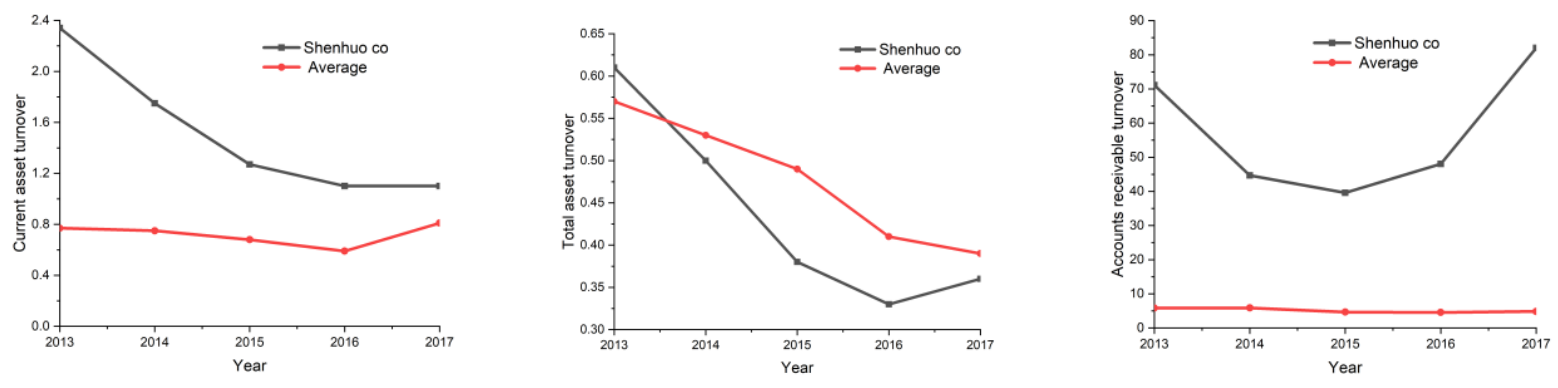

Fig.1 Current assets, total assets, accounts receivable turnover rate statistics of Shenhuo group

The current asset turnover rate is the rate of the net main business to the total current assets during a certain period. Table 2 shows that the turnover rate of Shenhuo's current assets is faster than the industry average. The higher the ratio is, the higher the utilization of funds and the lower operational risks is. The total asset turnover rate refers to the ratio of operating income to the average total assets. It can objectively and fully evaluate the use of total assets. The larger the value, the smaller the operational risk. Table 2 shows that the total asset turnover rate of Shenhuo group is lower than the industry average in the past four years, and it is falling year by year. The total asset turnover of enterprises is slow and there is the possibility of facing operational risks. Accounts receivable turnover rate refers to the ratio of the net sales of current sales to the average balance of accounts receivable, reflecting the average number of times that the company's accounts receivable is converted into cash within a certain period of time. It can be seen from Table 2 that the turnover rate of Shenhuo's accounts receivable in the past five years is much higher than the industry average, indicating that the company's return is relatively fast, and the flow of accounts receivable is very high, which reduces the operational risk to a certain extent. 
The risk of income distribution is related to the distribution of income. When a listed company allocates income, if it does not accurately grasp the time, method and amount of distribution, it will lead to a decrease in solvency and further financial risk.

Table 3 Income distribution risk indicator statistics

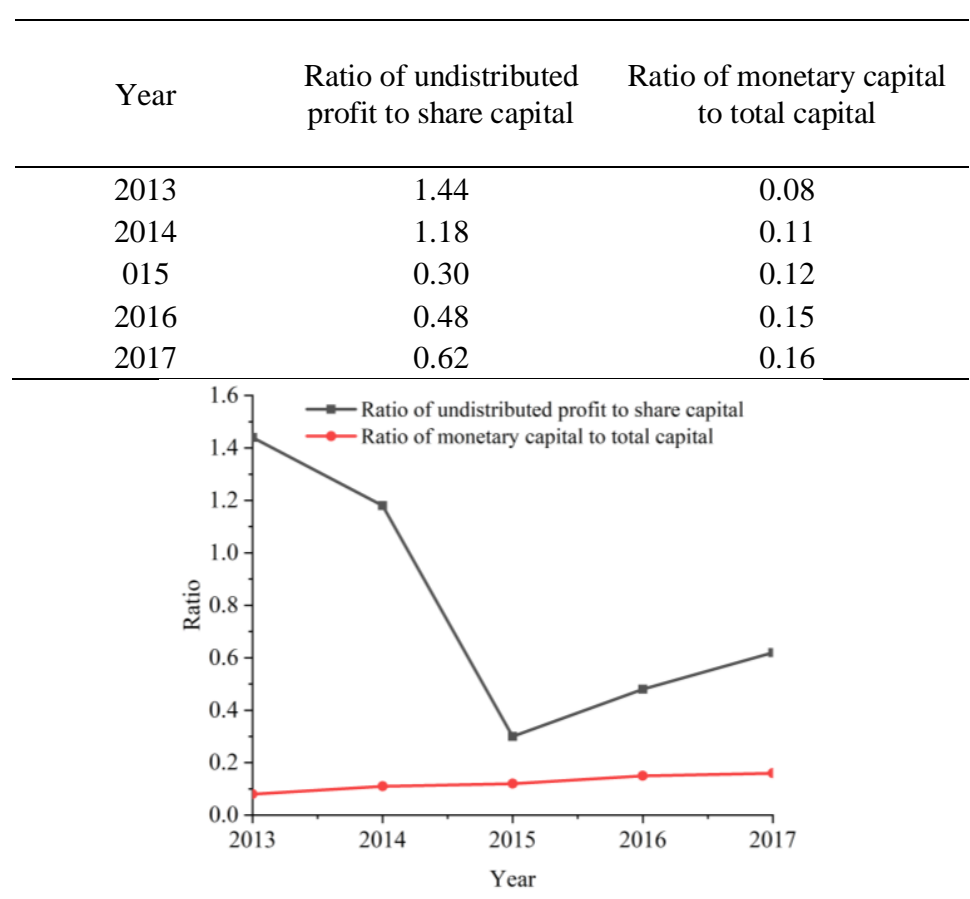

Fig.2 Ratio of monetary capital to total capital

The undistributed profit as a share capital ratio is the ratio of undistributed profit to equity, and the larger the value, the smaller the distribution risk may be. Table 3 shows that the undistributed profit share ratio of Shenhuo group has declined in the past five years, and the undistributed profit has decreased year by year, which may face the risk of income distribution. The proportion of monetary capital in total assets increases year by year, and the holding amount of corporate money funds increases year by year, which reduces the risk of income distribution to some extent.

\section{Finance risk analysis}

The short-term solvency and long-term solvency of Shenhuo group are not optimistic, and the risk of financing cannot be ignored. Shenhuo group currently adopts the business model of coal-electricityaluminum integrated operation. The company needs a large amount of working capital to ensure normal daily production and operation activities. Therefore, it is difficult to meet the needs of production and operation with its own funds, and only get the funds you need through financing. Generally speaking, the financing method includes equity financing and debt financing. Shenhuo group adopts debt financing according to various indicators. In this way, you can replenish your own funds at the fastest speed, maintain the continuity of the capital chain, and ensure the normal operation of the company. At the same time, it must bear the pressure to repay the principal and interest and face serious financial risks regardless of the company's operating efficiency. In short, companies do not consider all aspects before financing, but only seek rapid financing and fail to objectively weigh the pros and cons of the financing method, lacking financing plans. There is a lack of ability to randomly adjust funding plans in financing.

During the period of 2014-2015, the net profit of Shenhuo group was negative. On the one hand, due to the investment of RMB 2.2 billion in 2014, Shenhuo group transferred $100 \%$ equity of Henan Shenhuo Guangming Real Estate Development Co. Ltd., which is held by Henan Shenhuo Group Co. Ltd. The internal capital turnover of the enterprise has been difficult, and the cost is much larger than the income, which causes the enterprise to suffer losses and the investment risk is great. On the other hand, the corporate income statement shows that between 2014 and 2017, the company's sales 
expenses, financial expenses and management fees are huge, and the financial expenses rise year by year, resulting in the company's total asset growth rate lower than the industry average, further enhancing investment risks.

From the analysis results, the inventory turnover rate of Shenhuo group is relatively good in the industry, but there is still a certain gap between the excellent value and even the standard value. It can be seen that the inventory goods of the enterprise have been slow-moving, the inventory is too much, and the production cost has not been obtained in time. Compensation, companies may face difficulties in capital turnover and even cause operational risks. However, from the indicator of accounts receivable turnover, it is not always the case that it is far ahead in the industry. The reason why the ratio is so high is not because the return rate is fast, but because the amount of asset impairment loss of the enterprise is huge, and the amount of bad debts is high, resulting in a small amount of accounts receivable, resulting in a large ratio and rapid turnover. Based on the combination of two factors, it is possible that Shenhuo has the possibility of facing operational risks and deserves the attention of policy makers.

According to the analysis results, Shenhuo group have not distributed a small amount of profits in recent years. The reason is still related to the losses in recent years. Most of the company's net profit is used to make up for the previous year's profit and loss, resulting in a decrease in corporate dividends and undistributed profits. Drop down again. As a result, enterprises not only have not retained enough equity capital, but also because the profits distributed to shareholders are too small, but shareholders have doubts, lose confidence in the company, shake the internal unity, and affect the company's reputation to damage the stock price, causing a more serious financial crisis. Therefore, the probability of income distribution risk is high, Shenhuo group should respond quickly, formulate strategies to prevent problems before they occur.

\section{Financial risk response}

Shenhuo group must improve their fund-raising management capabilities, and can reduce their financing risks by improving financial leverage factors, asset-liability ratios and other indicators that have a significant impact on financing risks. According to the analysis results, the financing method of Shenhuo group is mainly debt financing. The primary choice is that the interest rate is much lower than that of privately financed bank loans. Bank loans can be rapid financing of enterprises and supplement the capital chain, but its drawbacks cannot be ignored. The process is complicated, the restrictions are numerous, and it has short-term, and the interest rate of bank loans is fixed. Regardless of whether the business is dynamic or not, it has to bear interest, so that it faces enormous pressure to return the principal and sub-fund and risk of financing. In order to reduce the risk of financing, the first thing Shenhuo group must do is to reduce the debt level, establish a reasonable capital structure system, and develop diversified financing channels. First, reduce bank loan financing, open up the coal industry bond market, and use stocks and bonds to finance and reduce repayment pressure. Second, learn advanced foreign ideas, set up investment funds, and gradually improve the multi-level financial system in which government intervention and market regulation complement each other, vigorously promote the development of the coal industry, ensure the integrity of the capital chain, strengthen cash flow, optimize debt structure, and reduce financing costs, thereby reducing financing risks. Third, it is possible to carry out portfolio financing, and various financing methods can complement each other's strengths, effectively speed up fundraising and diversify risks.

According to the analysis results, Shenhuo group have certain investment risks for investors. In order to eliminate investors' doubts and attract more investors to inject funds into enterprises, Shenhuo group is in urgent need of improving business methods, rationally allocating funds and improving. The financial leverage factor reduces the risk of investment. First, companies should save on fixed costs. Equipped with state-of-the-art equipment to increase worker productivity and increase production, reduce binding fixed costs, and use effective financial decisions to reduce discretionary fixed costs. In addition, through the improvement of mining methods, the introduction of new mining technology, the use of advanced and labor-saving mining tools, reduce mining costs and design costs, in addition to develop a sound quota management plan, optimize capital utilization, reduce losses in 
the production process, in order to reduce The purpose of the unit variable cost. Second, reduce financial costs through improved financing channels, improve internal organizational structure and reduce management fees, adopt new propaganda methods to reduce sales expenses, and allocate funds reasonably. Third, the sales department should make a reasonable plan to use the emerging and lowcost marketing channels such as the network to promote and promote the sales unit price while ensuring sales. On the other hand, enterprises should also pay attention to avoiding risks when investing abroad. Before making investment decisions, they must clarify the investment procedures, judge the feasibility of investment, and formulate feasible solutions. The scope of investment should be broad and should not be limited to the industry. The investment should be diverse and extensively involved, both to spread the risk and expand the market, increasing the possibility of profit.

According to the analysis, the operational risk of Shenhuo group mainly comes from two aspects: excessive internal inventory and low quality of receivables collection. To reduce operational risks, we must first improve the ability to recover funds. Increase the turnover rate of accounts receivable and shorten the collection period. First, it is necessary to strengthen the management of capital operations, reduce the possibility of bad debts, strengthen the liquidity of funds within the enterprise, and ensure that the company has a complete capital chain and can operate normally. Second, enterprises have passed the growth stage, need to develop new by-products, adjust sales strategies, and further extend and develop new markets based on existing sales channels. Clean up inventory and reduce internal inventory. The market demand for coal has a certain seasonality. The winter heating in northern China has increased the demand for coal to a certain extent. Therefore, enterprises should formulate mining plans, rationally mine according to the plan and the off-season season of demand, ensure that products can be sold in time, avoid backlog, reduce inventory, increase inventory turnover, and reduce operational risks.

The enterprise profit distribution plan is formulated based on the previous fundraising strategy, investment strategy, and business strategy. The operating conditions in recent years are not very good for Shenhuo group, and most of the profits are used to repay the previous years' profit and loss, resulting in a decrease in retained earnings. A large amount of debt, so that the asset-liability ratio is higher than the industry average, affecting the normal external financing of enterprises, and its own production and operation is also more dependent on operating profit, further reducing undistributed profits. In the future, Shenhuo group will formulate a long-term profit distribution plan to be used in different accounting years based on the improvement of financing methods. The difference is adjusted appropriately, but it is necessary to eliminate the random change of profit distribution plan.

\section{Conclusions}

In this paper, the ratio analysis method is used to identify and analyze the financing risks, investment risks, capital operation risks and income distribution risks taking Shenhuo group as a case study. The causes of the financial risks of Shenhuo group are determined and the response to risk is put forward. Shenhuo group has relatively small current assets, weak liquidity, and short-term solvency, facing certain financing risks. Shenhuo has suffered serious losses in recent years, and the growth rate of total assets is slow, facing certain investment risks. Based on the financial statement data of Shenhuo group for the past 5 years, this paper analyzes the financial status of Shenhuo group in recent years from four aspects: financing, investment, capital operation and income distribution, and identifies the existing and potential risks in the production and operation process. The risk management theory supports the analysis of existing problems and proposes countermeasures in a targeted manner, thereby avoiding the losses caused by financial risks, increasing the income, enhancing the core competitiveness of enterprises, and also managing financial risks of other enterprises and industries. It is helpful for the listed company to prevent and avoid financial risk decision-making.

\section{References}

[1] Hou X, Wang Q, Zhang Q. Market structure, risk taking, and the efficiency of Chinese commercial banks [J]. Emerging Markets Review, 2014, 20 (3): 75-88. 
[2] A. Olsen R. Financial risk perceptions: a consciousness perspective [J]. Qualitative Research in Financial Markets, 2014, 6 (1): 66-74.

[3] Eyiah A K, Cook P. Financing small and medium-scale contractors in developing countries: a Ghana case study [J]. Construction management and economics, 2003, 21 (4): 357-367.

[4] Harding J. Financial circumstances, financial difficulties and academic achievement among firstyear undergraduates [J]. Journal of Further and Higher Education, 2011, 35 (4): 483-499.

[5] Back P. Explaining financial difficulties based on previous payment behavior, management background variables and financial ratios [J]. European Accounting Review, 2005, 14 (4): 839868.

[6] Benini M, Sicari S. Risk assessment in practice: A real case study [J]. Computer Communications, 2008, 31 (15): 3691-3699.

[7] Wang Y. Financing difficulties and structural characteristics of SMEs in China [J]. China \& World Economy, 2009, 12 (2): 34-49. 